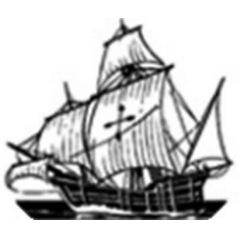

\title{
O PROTÓTIPO DA MALANDRAGEM NO CORDEL ENCONTRO DE CANCAO DE FOGO COM PEDRO MALASARTES
}

\author{
Maria José Lopes Pedra ${ }^{1}$
}

RESUMO: A literatura de cordel é um gênero literário popular que aborda temas como; a novela, a política, a culinária, fatos do dia-a-dia, e, acontecimentos históricos que são (re)lembrados por meio de ações heroicas de personagens do folclore português/brasileiro. $\mathrm{Ou}$ seja, tal literatura serve como fonte de informação, que tem como objetivo levar ao povo diferentes visões de mundo. Neste trabalho, objetiva-se expor argumentos reflexivos sobre a malandragem presente no cordel Encontro de Cancão de Fogo com Pedro Malasartes, de Minelvino Francisco Silva (1957), propondo, assim, ressaltar a importância das personagens para a sociedade atual. Tanto Pedro Malasartes, quanto Cancão de Fogo se destacam nas histórias por suas características pitorescas. Malasartes é símbolo de resistência em diversos países, onde suas narrativas sempre levam um cunho de crítica social. Cancão de Fogo é um anti-herói, considerado o porta-voz da classe menos favorecida, uma vez que ele usa de suas malandragens e astúcias para combater os opressores. As características apresentadas em ambos os personagens, servem para desconstruir a ideia de que o sertanejo é desprovido de inteligência, pois eles constroem suas armas por meio da criatividade, armas essas, que sempre acabam dando certo no decorrer das aventuras. Sendo assim, esses personagens são figuras do folclore brasileiro que se utilizam da astúcia e da inteligência para sobressair-se em diversas situações. Pedro Malasartes e Cancão de Fogo adquirem as características de antiherói e do malandro que vão contra a ascensão e a ordem social vigente, agindo, assim, em prol da sobrevivência. Tais personagens passam da oralidade para a escrita, contribuindo, para formação cultural de um povo. Por esta ótica, Cancão de Fogo e Pedro Malasartes são figuras muito presentes nos cordéis, surgindo como reflexo do sertanejo que é visto como inferior pela classe dominante. Desse modo, analisa-se nesse trabalho toda a construção simbólica das personagens no cordel, evidenciando traços relacionados ao povo nordestino. Partindo desta constatação, fez-se necessária uma pesquisa bibliográfica, pautando-se nas teorias de Haurélio (2010), Da Matta (1997), Abreu (2004), Cascudo (1979, 2000), e Cândido (1970) que fundamentam esse artigo. Assim, verificou-se que a malandragem explícita no cordel se faz presente para evidenciar os divergentes problemas sociais onde as pessoas que fazem parte da classe menos favorecida, muitas vezes, tende a contar com o jeitinho a fim de conseguir seus objetivos.

\footnotetext{
1

Graduanda do curso de Letras Vernáculas da Universidade do Estado da Bahia UNEB, Campus Universitário Professor Gedival de Sousa Andrade. E-mail: Marialopes_pedra@hotmail.com
} 
PALAVRAS-CHAVE: Cordel. Malandragem. Cancao de Fogo. Pedro Malasartes.

SUMMARY: The Cordel literature is a popular literary genre that covers topics such as; novel, politics, cooking, facts of day-to - day, and historical events that are ( re) reminded through actions of heroic characters folklore Portuguese/Brazilian. Ie such literature serves as a source of information, which aims to bring people to different worldviews. In this work, we aim to expose reflexive arguments about the trickery in this string Meeting Song of Fire with Pedro Malasartes of Minelvino Francisco Silva (1957), proposing thus emphasize the importance of characters for today's society. Both Pedro Malasartes, the Song of Fire stand out in the stories for their picturesque features. Malasartes is symbol of resistance in many countries, where their narratives always carry a stamp of social criticism. Song of Fire is an anti - hero, considered the spokesman underprivileged class, since it uses its foibles and wiles to fight the oppressors. The characteristics presented in both characters serve to deconstruct the idea that the backcountry is devoid of intelligence as they build their weapons through creativity, these weapons, which always end up working out in the course of the adventures. Therefore, these characters are figures of Brazilian folklore that use of cunning and intelligence to excel in various situations. Pedro Malasartes Song of Fire and acquire the characteristics of anti - hero and trickster who go against the rise and social order, thus acting in the interests of survival. These characters move from orality to writing, contributing to cultural education of a people. On this view, Song of Fire and Pedro Malasartes figures are very present in twine, arising as a result of the backcountry that is seen as inferior by the dominant class. Thus, this paper analyzes the symbolic construction of all characters in the string, showing traces related to the people of the Northeast. Based on this finding, it was necessary a literature search, basing on the theories of Haurélio (2010), Da Matta (1997), Abreu (2004), Shelly (1979 , 2000), and Cândido (1970) that underlie this article. Thus, it was found that the trickery in explicit string is present to highlight the divergent social problems where people who are part of the least favored class, often tends to have the knack to achieve their goals.

KEYWORDS: Cordel. Trickery. Cancao Fire. Pedro Malasartes.

\section{INTRODUÇÃO}

A Literatura de Cordel é um gênero literário popular que tem como objetivo levar ao povo diferentes visões de mundo. Tal Literatura aborda temas como a novela, a política, a 
culinária, fatos do dia-a-dia e acontecimentos históricos que são (re)lembrados por meio de ações heroicas de personagens do folclore português/brasileiro. Desse modo, a questão central do cordel Encontro de Cancao de Fogo com Pedro Malasartes é que os personagens apresentam características típicas da malandragem, para mostrar a desigualdade social frequente em diversas regiões.

Por esta ótica, Cancao de Fogo e Pedro Malasartes são figuras cômicas muito presentes nos cordéis, surgindo como reflexo do sertanejo que é visto como inferior pela classe dominante. Esses personagens são símbolos de resistência que, com suas características próprias, combatem os empecilhos que surgem em suas vidas.

O estudo desse tema torna-se importante para a divulgação e a valorização da literatura de cordel, sendo relevante, também, para abrir um leque de informações e discussões sobre as questões culturais, retomando certas raízes da formação do povo nordestino. Desse modo, o cordel é uma literatura de grande valor para a percepção da identidade desse povo, já que está ligada ao imaginário e ao conhecimento popular.

O presente artigo elabora um estudo acerca das narrativas de Cancao de Fogo e Pedro Malasartes presente no cordel Encontro de Cancao de Fogo com Pedro Malasartes, de Minelvino Francisco Silva (1957). Como suporte teórico, tem-se Abreu (1999), que esclarece pontos fundamentais sobre a Literatura de Cordel; Da Matta (1997), salientando as questões referentes às características de Pedro Malasartes; Haurélio (2010), que aborda pontos fundamentais sobre Cancão de Fogo e sobre o cordel, dentre outros.

\section{A REPRESENTAÇÃO EM CORDEL DA FIGURA DO MALANDRO NO SERTÃO NORDESTINO}

No Brasil, as manifestações culturais e personagens míticos do folclore nacional estão impregnadas em diversos lugares, principalmente no Nordeste, evidenciando o sofrimento e a resistência do povo que constitui essa região.

Abreu (1999) entende que é na Literatura de Cordel que o povo expressa seus sentimentos, relata fatos históricos e tudo aquilo que é passivo à oralidade e à escrita. Para esta autora, a Literatura de Cordel não se destina somente às camadas populares, mas 
interessa, também, à elite que, por sua vez, utiliza o cordel como fonte de lazer e de conhecimento.

Segundo Haurélio, a Literatura de Cordel é a reprodução da poesia popular, uma vez que esta relata tema da tradição oral de uma dada época, com certas raízes no trovadorismo medieval lusitano: "Os temas de cordéis são os mais variados, até porque os seus artistas retratam aquilo que veem, sentem ou imaginam" (2010, p. 102).

Neste sentido, Malasartes e Cancão surgem como forma de crítica social, para mostrar os problemas referentes à desigualdade econômica. No cordel Encontro de Cancao de Fogo com Pedro Malasartes, Silva (1957) tem a intenção de juntar esses dois pícaros do folclore brasileiro, para mostrar os problemas sociais que afligem, principalmente, o homem do campo.

Cancão de Fogo e Pedro Malasartes simbolizam os primeiros pícaros sertanejos, sendo estes modelos a serem seguidos pelos personagens que se seguiram nos enredos de cordel. $\mathrm{O}$ antropólogo Da Matta (1997) afirma que o personagem Pedro Malasartes pode ser visto como uma figura do protótipo do malandro e do herói, pois fica difícil saber o que é certo e o que é errado, o que é justo e o que é injusto já que o personagem age sempre para alcançar seus objetivos não se importando com a lei social vigente.

Segundo Haurélio (2010), Cancão de fogo, criação de Leandro Gomes de Barros, é considerado um anti-herói. Trata-se de uma personagem amoral, quando logra pessoas, como um juiz, um escrivão e um padre. Estudos apontam que Cancão de Fogo é o porta-voz da classe menos favorecida, uma vez que ele utiliza de suas malandragens e astúcias para combater os opressores.

Cascudo (1979) afirma que o personagem Cancão de Fogo é uma espécie matuta do Lazarillo de Tormes, Guzmán de Alfarache ou Estebanillo Gonzáles, personagens considerados quengos finos da velha Europa.

Pedro Malasartes é um personagem do folclore português/brasileiro que, da oralidade, passou para os cordéis e para as antologias de literatura popular, como as de Câmara Cascudo (2000), primeiro autor que reuniu cinco narrativas do personagem em sua obra Contos tradicionais do Brasil.

Pedro Malasartes é também conhecido pelas suas artimanhas. Ele é símbolo de resistência em diversos países, onde suas histórias sempre levam um cunho de crítica social. Malasartes é a personificação do bem e do mal. Segundo Da Matta (1997), esse personagem é 
considerado um personagem sem caráter, e sem escrúpulos, que, utilizando-se de suas astúcias, consegue driblar os divergentes problemas sociais.

Pedro Malasartes e Cancão de Fogo adquirem as características de anti-herói e do malandro que vão contra a ascensão e a ordem social vigente, agindo assim, em prol da sobrevivência. No cordel, Cancão de Fogo residia na Paraíba do Norte, já Pedro Malasartes perambulava pelas terras do Ceará até Belém do Pará, características típicas desse último personagem que, "não podendo ficar sossegado, Malasartes largou a casa indo correr mundo" (CASCUDO. 2000 p. 125).

Esses dois malandros pensaram em ganhar a vida no sertão, já que, para eles, o homem do campo é bobo e inocente. Essa ideia trazida pelos personagens sobre o povo do interior nordestino é respalda na visão estereotipada que se tem dessa região, ou seja, muitos a veem como pessoas fáceis de serem enganadas.

Com os planos traçados, Malasartes leva um fardo de molambo com tecidos velhos e rasgados, e prepara-se para enganar o primeiro que encontrar. Cancao, diante um lixão da feira livre, encontrou um fardo de espinhas de pescado, quando o empacotou para dar o golpe no povo dizendo que era peixe.

“O malandro, como o pícaro, é uma espécie de um gênero mais amplo de aventureiro astucioso, comum a todos os folclores" (CANDIDO, 1970, P. 15). Sendo assim, a malandragem está explícita nas atitudes desses dois personagens que, utilizando-se de suas astúcias, tentam sobreviver numa sociedade profundamente desigual.

Durante a narrativa, esses dois personagens seguem cada um o seu caminho, quando acabam encontrando-se no sertão. Sem conhecerem a história do outro, Cancão e Pedro tentam colocar seus planos em ação. Esses dois malandros resolvem trocas os fardos, um achando que estava trapaceando o outro, quando, na verdade, os dois foram logrados. Cancão de Fogo e Pedro Malasartes jamais nessa vida foram enganados e, assustados com o ocorrido, pensaram em se encontrar para, juntos, roubarem rico, pobre, padre e sacristão.

No cordel, Cancão de Fogo e Pedro Malasartes de fome não morre. Sem dinheiro, eles não ficam, pois a mentira e a dissimulação são características próprias desses personagens. É importante ressaltar, que essas figuras não se apropriam de armas ou poderes mágicos, eles se transformam no reflexo do homem simples que tende a driblar os problemas da vida através da inteligência. 
No entanto, Cancão de Fogo e Pedro Malasartes criaram uma armadilha a fim de conseguir lograr o povo do sertão. Malasartes lança a ideia de Cancão se fingir de cego e ele de aleijado para, assim, pedirem esmola, atividade esta que alguns morados de rua com deficiência física ou visual realizam em prol de sobrevivência.

Nesta perspectiva, volta-se um olhar para a sociedade atual, percebendo-se que existem pessoas representantes da classe desfavorecida, que, de fato, atuam como esses dois personagens pícaros do cordel, uma vez que esses povos fingem adquirir algum tipo de deficiência para conseguir dinheiro, comidas e vestimentas.

Com a invenção do momento, Malasartes deu um jeitinho na perna, colocando "a batata para frente e a canela virada" (SILVA, 1957), que ficou idêntica a de um aleijado. Cancão de Fogo se intitulou como Serapião, dando um jeitinho nos olhos, assim, fingiu-se de cego. Pedro, que supostamente estava com uma deficiência na perna, puxava Cancão pelo bastão, com o intuito de aplicar o golpe nos moradores da região.

As histórias de Pedro Malasartes e Cancão de Fogo fazem uma leitura da realidade social, criticando-a através do humor que predomina durante a narrativa. Isso acontece com os mitos que, por meio de narrativas orais, perpassam à sociedade um cunho de crítica sobre um determinado fator histórico/cultural.

Colocando o plano em ação, os astutos, no caminho, encontraram dois tropeiros que iam levando cinco fardos de mercadorias e, estes, com pena dos dois malandros, entregaram comidas a eles até se fartarem. Malasartes e Cancão agiram com esperteza para enganar os tropeiros, ou seja, eles roubaram os fardos de mercadorias e os esconderam na serra do espigão. Os tropeiros procuraram a mercadoria e, não encontrando nem os fardos e nem o suspeito, não poderiam desconfiar de um cego e de um aleijado.

A trapaça, a dissimulação e a desonestidade são termos que estão explícitos nas aventuras desses malandros, uma vez que eles passam por cima da ordem social para beneficiar-se com objetos alheios.

Desse modo, Pedro fala a Cancão para ir até a cidade alugar uma loja e, depois, negociarem. Assim, Cancão fez, e Pedro, muito sagaz e astuto, logo tenta roubar o companheiro de andanças, escondendo os fardos em outro lugar. Quando Cancão percebe que foi roubado, exclama com muita tristeza:

Eu nunca fui enganado

Tenho vinte e cinco anos 
Sem ninguém ter me logrado

Malasartes me roubar

Isso é que acho pesado.

Já vi que é certo o ditado

Da gente do interior

Que por detrás de pau grosso

Tem outro superior [...] (SILVA, 1957), p. 09).

Nessa estrofe, podem-se perceber as características típicas de Pedro Malasartes, um amoral, sem caráter, dissimulado, mentiroso e muito sabido. Malasartes, sem escrúpulo algum, ludibria o próprio ludibriador, o seu companheiro de andanças, Cancão de Fogo, pois já dizia Da Matta (1997), no seu livro Carnavais, malandros e heróis, que o malandro parte de um gesto simples de sagacidade até pequenos golpes profissionais, caracterizando-se, muitas vezes, como desonesto, quando o malandro deixa de viver do jeitinho para sobreviver de golpes, tornando-se assim, um marginal. Ainda este autor esclarece que a malandragem é totalmente carregada de improvisos, como pode ser percebido nessa ação de Malasartes com Cancão, quando Pedro aproveita da suposta amizade para roubá-lo.

Para Da Matta (1997), Malasartes é um personagem sem nenhum caráter, assim como Macunaíma e Leonardo, figuras cômicas da literatura brasileira. Mário de Andrade, autor, da obra Macunaíma, constrói o personagem como a figura que representa o povo brasileiro. Tal personagem é considerado um herói sem nenhum caráter que adquire diferentes identidades durante suas aventuras. Já Leonardo, criação de Manoel Antônio de Almeida, é um personagem considerado indubitavelmente pícaro, pois à medida que se depara com a realidade, resolve seguir o caminho da desordem social.

Neste sentido, Pedro Malasartes junto com esses personagens, constrói o rol das figuras astutas, bebendo, assim, da mesma fonte para sobreviverem num mundo tão profundamente dividido.

Pedro Malasartes enriquece-se culturalmente através de suas jingas e malandragens para lutar contra os poderosos, ele adquire a característica de anti-herói por ficar na intermediária entre a ordem e a desordem, sem ter como saber o que é certo e o errado. O que importa para esse personagem é resolver o problema, sobressaindo-se bem em qualquer situação.

Diante dessa perspectiva, Cancão de Fogo resolve se vingar de Malasartes, isto é, ele fez uma cilada para conseguir se encontrar-se com Pedro para este se explicar, mas logo o 
malandro se livra com sua arte de enganar, e diz ao amigo ter escondido os fardos, pois tinha alguém os observando.

Cancao mandou que Pedro descesse para amarrar os fardos de um a um que Ele ia puxar e, assim exercer sua vingança, quando a sua intenção era deixá-lo na armadilha. Mas, Malasartes logo saiu do buraco amarrado junto ao quarto saco:

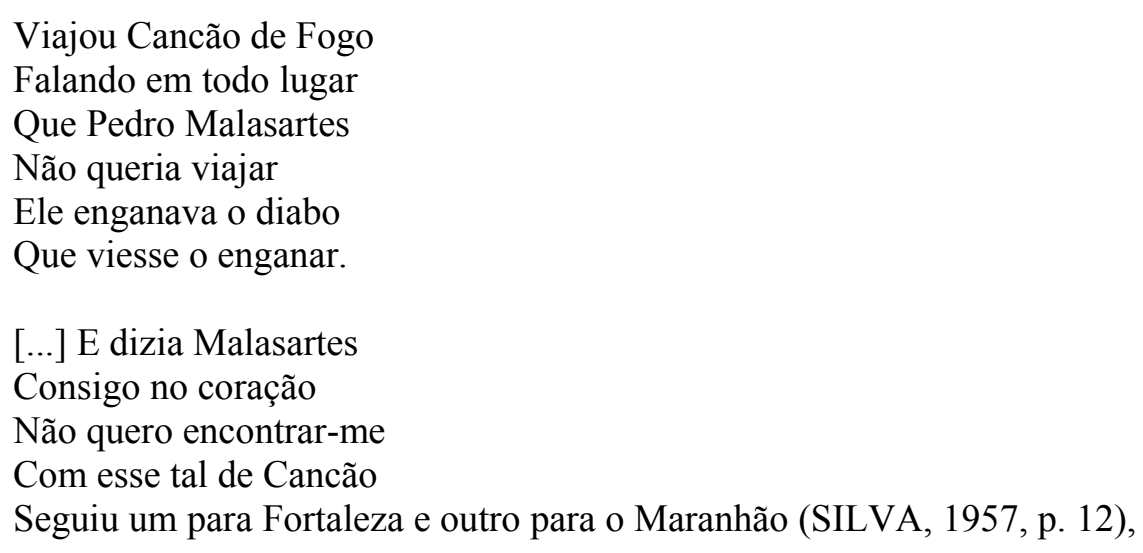

Face ao exposto, percebe-se que os dois personagens são conhecidos como malandros que contam com astúcia e a dissimulação, como forma de sobrevivência. No cordel, Pedro Malasartes demonstra ser mais esperto e sagaz em relação à Cancão de Fogo, uma vez que Malasartes atua como o malandro que domina as situações em toda narrativa.

\section{CONSIDERAÇÕES FINAIS}

Por meio da Literatura de Cordel, é possível perceber e identificar diversos fatos corriqueiros na sociedade, como os problemas econômicos que afligem determinadas populações, ou seja, além de informativo, o cordel também surge como uma crítica à sociedade.

Por essa ótica, o cordel Encontro de Cancão de Fogo com Pedro Malasartes faz críticas à questão da desigualdade socioeconômica por meio dos personagens pícaros do folclore brasileiro, Pedro Malasartes e Cancão de Fogo.

Pedro e Cancão de Fogo, além de atuarem como pícaros defendem a sua imagem, uma vez que desconstroem o conceito presente na narrativa de que sertanejo é bobo e inocente, já 
que tais personagens também são caipiras do Nordeste brasileiro e adquirem as características de esperto e de inteligente.

Portanto, Pedro Malasartes e Cancão de Fogo são personagens, que por falta de trabalho remunerado, resolvem ganhar a vida por meio da malandragem, aplicando golpes aos membros referentes a todas as classes sociais. Sendo assim, a malandragem se faz presente como arma típica desses personagens que, sem força e nem poder, têm que contar sempre com sua esperteza.

\section{REFERENCIAS}

ABREU, Márcia. História de cordéis e folhetos. Camponas: Mercado de Letras, 1999.

ANDRADE, Mário de. Macunaíma, o herói sem nenhum caráter. Rio de Jnaiero: Agir, 2008.

CÂNDIDO, Antônio. Dialética da Malandragem. 8. Ed. São Paulo: USP, 1970.

. Conco Livros do Povo. 2. Ed. João Pessoa: Editora UniversitáriaUEPb, 1979.

HAURÉLIO, Marco. Breve História da Literatura de Cordel. São Paulo: Claridade, 2010.

MATTA, Roberto Da. Carnavais, malandros e heróis: para uma sociologia do dilema brasileiro. 6. Ed. Rio de Jnaiero: Rocoo, 1997.

SILVA, Minelvino Francisco, Encontro de Cancao de Fogo com Pedro Malasartes. São Paulo: Prelúdio, 1957. 
